Polymer Journal, Vol. 39, No. 7, pp. 731-736 (2007)

(C) 2007 The Society of Polymer Science, Japan

\title{
Synthesis and Property of Poly(arylene sulfone)s Containing 9,9-Diarylfluorene Moiety in the Main Chain
}

\author{
Surasak SEESUKPHRONRARAK and Toshikazu TAKATA ${ }^{\dagger}$ \\ Department of Organic and Polymeric Materials, Tokyo Institute of Technology, \\ 2-12-1 H-126 Ookayama, Meguro-ku, Tokyo 152-8552, Japan
}

(Received January 9, 2007; Accepted April 15, 2007; Published May 29, 2007)

\begin{abstract}
Poly(arylene sulfone)s (PASs) were synthesized in quantitative yields by the oxidations of the corresponding fluorene-containing poly(arylene thioether)s, derived from 9,9-diarylfluorene-based dithiols and dihaloarenes, with 30\% hydrogen peroxide in formic acid. PASs had good solubility in common organic solvents such as chloroform, $N$-methylpyrrolidone (NMP), and $N, N$-dimethylformamide (DMF). Highly transparent films were obtained by casting the chloroform solutions of PASs. PASs exhibited high glass transition and high decomposition temperatures ( $\mathrm{T}_{\mathrm{g}} 248-355^{\circ} \mathrm{C}, \mathrm{T}_{\mathrm{d} 5}>400^{\circ} \mathrm{C}$ under nitrogen). [doi:10.1295/polymj.PJ2006211]

KEY WORDS Poly(arylene thioether) / Poly(arylene sulfone) / 9,9-Diarylfluorene / Thermal Stability / Solubility /
\end{abstract}

Increasing interest has been devoted to the syntheses of high performance polymers with special property including poly(arylene sulfone)s as amorphous engineering thermoplastics. Poly(arylene sulfone)s possess excellent properties such as mechanical strength, hydrolytic stability, low flammability, and oxidative stability, making them wildely useful in various applications. ${ }^{1}$ For example, they could be the basic materials for porous and dense polymeric membranes required for gas separation or fuel cell application. ${ }^{2}$ Some polysulfones are commercially available as high performance engineering plastics such as $\mathrm{UDEL}^{\circledR}{ }^{\circledR}, \mathrm{VICTREX}^{\circledR}, \mathrm{RADEL}^{\circledR}$, and so on. Aromatic polysulfones are often synthesized by direct polymerization via aromatic nucleoplilic substitution of the corresponding bis(fluoroaryl)sulfones and bisphenols as monomers. ${ }^{3}$ Ueda et al. ${ }^{4}$ have reported the synthesis of aromatic poly(ether sulfone)s from nickel complex-mediated aromatic coupling polymerization of aromatic dichloride. An alternative way of making poly(arylene sulfone)s involves oxidation of poly(arylene thioether)s with hydrogen peroxide in formic acid. ${ }^{5,6}$ By the replacement of thioether function with sulfone function in polymer main chain, it is expected that sulfone polymer shows, e.g., glass transition temperature $\left(\mathrm{T}_{\mathrm{g}}\right)$ higher than the corresponding thioether polymer. Meanwhile, polymers containing 9,9-diarylfluorene moieties in the main chain have collected much interest because of their excellent properties such as high solubility and good optical properties based on the cardo structure of the 9,9-diarylfluorene moiety. ${ }^{7}$ Since polysulfones are usually hard to be soluble in ordinary organic solvents, the introduction of the fluorene skeleton seems to improve the solubility of polysulfones in addition to endowment of good optical property. We have recently prepared 9,9-diarylfluorene-based poly(arylene thioether)s with excellent physical and optical properties. ${ }^{8}$ As far as we know, no data has been reported by using of poly(arylene thioether)s containing 9,9diarylfluorene to obtained poly(arylene sulfone)s. Therefore, we have undertaken the synthesis of poly(arylene sulfone)s by the oxidation of the poly(arylene thioether)s, judging from the ease of procedure. This report describes the synthesis and characterization of 9,9-diarylfluorene moiety-based poly(arylene sulfone)s obtained by the oxidation of the corresponding poly(arylene thioether)s.

\section{RESULTS AND DISCUSSION}

Synthesis of 9,9-diarylfluorene-based poly(arylene thioether)s (PTEs) was carried out by the polycondensation of 9,9-bis( $N, N$-dimethyl-S-carbamoylphenyl)fluorenes and difluoroarenes, according to our previous report. ${ }^{8}$ The structures of the difluoroarenes employed for the PTE synthesis are shown in Scheme 1. The yields of PTEs were always quantitative. PTEs used as starting materials had the molecular weights ranging from 28,800 to 128,000 . A series of poly(arylene sulfone)s (PASs) were prepared according to Scheme 1 by heating PTEs with $30 \%$ hydrogen peroxide in $90 \%$ formic acid at $50^{\circ} \mathrm{C}$ for $2 \mathrm{~h}$. The white solid products were filtrated and washed with methanol to give PASs as white fibrous solids in quantitative yield. The comparison of GPC data of PTEs and PASs suggested little change in molecular weight before and after the oxidation. Although it is

${ }^{\dagger}$ To whom correspondence should be addressed (Tel: +81-35-734-2898, Fax: +81-35-734-2888, E-mail: takata.t.ab@m.titech.ac.jp). 

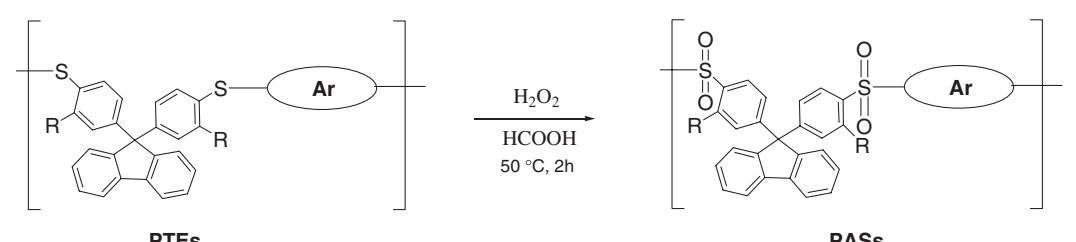

\begin{tabular}{|l|c|c|c|c|}
\hline & Polymer & R & Polymer & R \\
\hline
\end{tabular}

Scheme 1.

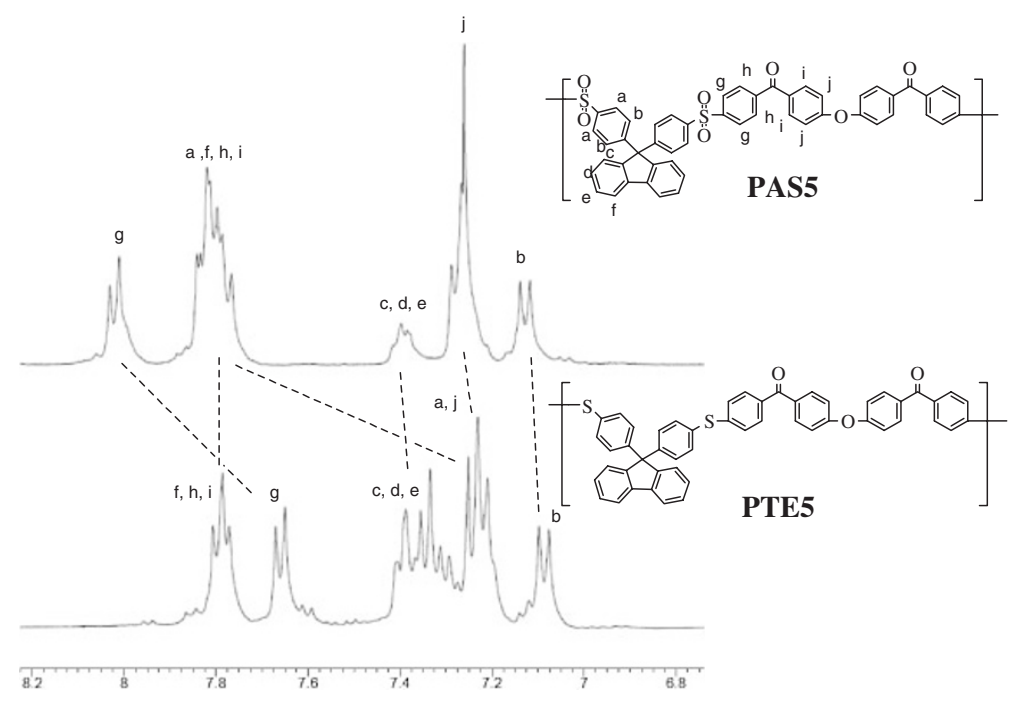

Figure 1. Selected ${ }^{1} \mathrm{H}-\mathrm{NMR}$ spectrum of PAS5 and PTE5.

not complete comparison due to the structural difference of them and the estimated values based on polystyrene standards, the observed GPC change seems small enough to suggest that the oxidation process does not give rise to the serious change in polymer structure: no cleavage of polymer main chain of PESs occurs during the oxidation.

The structures of PASs were confirmed by the FTIR, in which all PASs showed characteristic bands around $1150 \mathrm{~cm}^{-1}$ and $1320 \mathrm{~cm}^{-1}$ due to the stretching vibrations of the $\mathrm{SO}_{2}$ group. Typical ${ }^{1} \mathrm{H}-\mathrm{NMR}$ spectrum (PAS5) is shown in Figure 1. Because of the strong electron-withdrawing nature of the sulfone groups, the aromatic proton chemical shifts adjacent to the sulfone groups of PASs shifted to much lower field compared with those of their precursors PTEs. The thermal properties of PASs were characterized by thermogravimetric analysis (TGA) and differential scanning calorimetry (DSC). TGA revealed good thermal stability of PASs, which displayed onset decomposition temperature up to 400 and $380^{\circ} \mathrm{C}$ in nitrogen and air atmospheres, respectively (Figure 2). As shown in Table I, 5\% weight loss temperatures $\left(\mathrm{T}_{\mathrm{d} 5}\right)$ were in a range of $404-537^{\circ} \mathrm{C}$ and $386-512^{\circ} \mathrm{C}$ in ni- 
Synthesis of Fluorene-Containing Poly(arylene sulfone)s

Table I. Thermal properties of PASs and PTEs

\begin{tabular}{cccccccccccc}
\hline Polymer & $\begin{array}{c}M_{\mathrm{w}}{ }^{\mathrm{a}} \\
\times 10^{4}\end{array}$ & $\begin{array}{c}M_{\mathrm{n}}{ }^{\mathrm{b}} \\
\times 10^{4}\end{array}$ & $\begin{array}{c}\mathrm{T}_{\mathrm{g}} \\
\left({ }^{\circ} \mathrm{C}\right)^{\mathrm{c}}\end{array}$ & $\begin{array}{c}\mathrm{T}_{\mathrm{d} 5} \\
\left(\mathrm{~N}_{2}\right)^{\mathrm{d}}\end{array}$ & $\begin{array}{c}\mathrm{T}_{\mathrm{d} 5} \\
(\mathrm{Air})^{\mathrm{d}}\end{array}$ & Polymer & $\begin{array}{c}M_{\mathrm{w}} \\
\times 10^{4}\end{array}$ & $\begin{array}{c}M_{\mathrm{n}} \\
\times 10^{4}\end{array}$ & $\begin{array}{c}\mathrm{T}_{\mathrm{g}} \\
\left({ }^{\circ} \mathrm{C}\right)\end{array}$ & $\begin{array}{c}\mathrm{T}_{\mathrm{d} 5} \\
\left(\mathrm{~N}_{2}\right)\end{array}$ & $\begin{array}{c}\mathrm{T}_{\mathrm{d} 5} \\
(\mathrm{Air})\end{array}$ \\
\hline PTE1 & 9.8 & 4.4 & 275 & 553 & 522 & PAS1 & 9.5 & 5.2 & 355 & 477 & 473 \\
PTE2 & 12.8 & 4.0 & 217 & 508 & 498 & PAS2 & 7.5 & 3.2 & 275 & 493 & 435 \\
PTE3 & 3.3 & 1.6 & 216 & 532 & 519 & PAS3 & 2.6 & 1.5 & 290 & 520 & 499 \\
PTE4 & 10.8 & 3.6 & 229 & 551 & 524 & PAS4 & 8.4 & 4.0 & 304 & 511 & 512 \\
PTE5 & 6.1 & 1.9 & 212 & 540 & 526 & PAS5 & 5.2 & 2.6 & 282 & 537 & 507 \\
PTE6 & 3.4 & 1.6 & 252 & 439 & 447 & PAS6 & 2.8 & 1.6 & 296 & 404 & 395 \\
PTE7 & 7.3 & 2.5 & 215 & 448 & 443 & PAS7 & 4.7 & 2.1 & 248 & 421 & 387 \\
PTE8 & 2.9 & 1.2 & 212 & 511 & 463 & PAS8 & 3.5 & 1.6 & 267 & 410 & 389 \\
PTE9 & 3.6 & 1.7 & 221 & 537 & 474 & PAS9 & 4.2 & 1.9 & 280 & 415 & 392 \\
PTE10 & 10.5 & 3.1 & 210 & 466 & 466 & PAS10 & 10.6 & 3.8 & 258 & 413 & 386 \\
\hline
\end{tabular}

${ }^{\mathrm{a}} M_{\mathrm{w}}$ : weight-average molecular weight estimated by GPC based on polystryrene standards. ${ }^{\mathrm{b}} M_{\mathrm{n}}$ : Number-average molecular weight estimated by GPC based on polystryrene standards. ${ }^{\mathrm{c}} \mathrm{DSC}$ measurement was conducted at a heating rate $10^{\circ} \mathrm{C} / \mathrm{min}$ in $\mathrm{N}_{2}$ and air atmosphere. ${ }^{\mathrm{d}}$ TGA was carried out at a heating rate of $10^{\circ} \mathrm{C} / \mathrm{min}$.

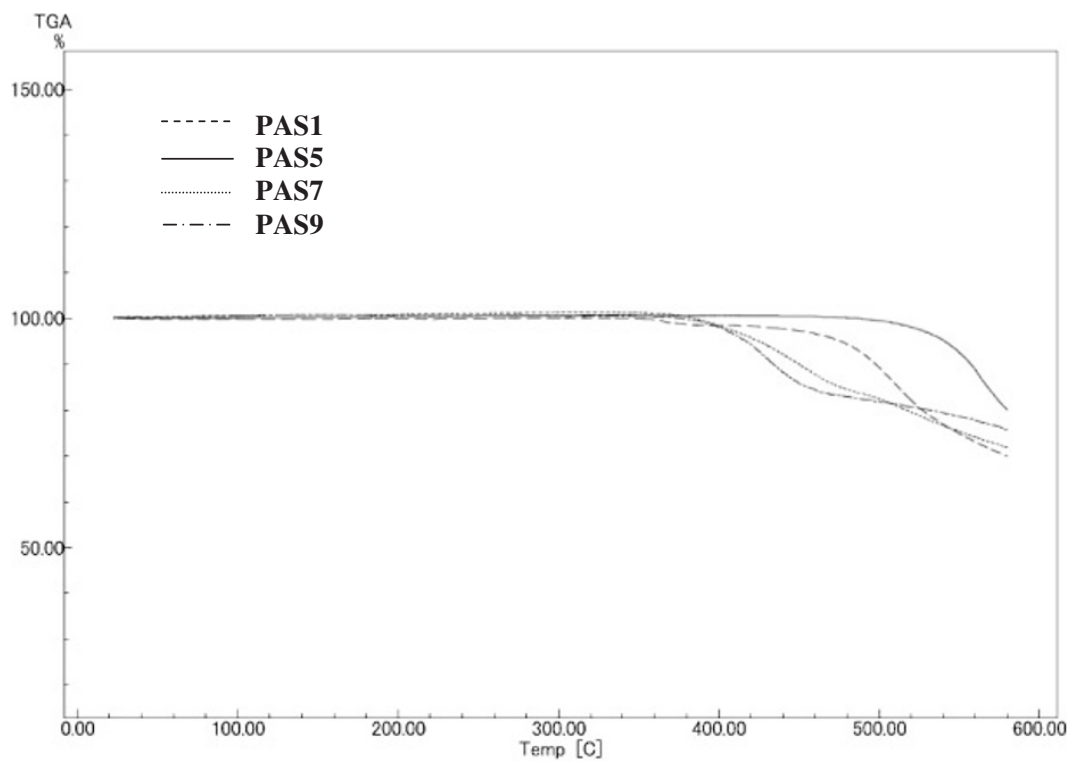

Figure 2. Selected TGA thermograms of PAS1, 5, 7 and 9. Heating rate: $10^{\circ} \mathrm{C} / \mathrm{min}$ in nitrogen atmosphere.

trogen and air atmosphere, respectively. The thermal stability of PAS was always lower than that of the corresponding PTE in most cases, probably because PTE has thermosetting property in contrast to PAS. ${ }^{9}$ The DSC study of PASs with a scanning rate of $10^{\circ} \mathrm{C} /$ min under a nitrogen atmosphere indicated that all PASs were not crystalline but amorphous. The glass transition temperature $T_{g}$ of PASs was in a range from 248 to $355^{\circ} \mathrm{C}$, depending on their structures. Inspection of the data in Table I reveals the $\mathrm{T}_{\mathrm{g}} \mathrm{s}$ of PASs $40-80^{\circ} \mathrm{C}$ higher than those of PTEs, indicating that the incorporation of the sulfone moiety significantly increases the polymer chain rigidity. PAS1 which contains oxadiazole moiety on the polymer backbone had the highest $\mathrm{T}_{\mathrm{g}}$ of $355^{\circ} \mathrm{C}$, probably due to the enhanced rigidity of PAS1 by the heterocyclic moiety compared with other PASs, indicating the sufficient rigidity derived by the sulfone function of the PAS1 structure. Thermal properties of PASs were compared with those of commercial polysulfones (Udel ${ }^{\circledR}-\mathrm{P} 1700$ : $\mathrm{T}_{\mathrm{g}} 190^{\circ} \mathrm{C}, \mathrm{T}_{\mathrm{d} 10} 523^{\circ} \mathrm{C} ; \mathrm{PES}^{\circledR}-5200 \mathrm{P}: \mathrm{T}_{\mathrm{g}} 220^{\circ} \mathrm{C}, \mathrm{T}_{\mathrm{d} 10}$ $\left.555^{\circ} \mathrm{C}\right) .{ }^{10}$ Since $\mathrm{T}_{\mathrm{g}}$ of PASs ranges from 282 to $355^{\circ} \mathrm{C}$ (for $\mathrm{R}=\mathrm{H}$ ) or from 248 to $296^{\circ} \mathrm{C}$ (for $\mathrm{R}=$ Me) (Table I), PASs have considerably higher glass transition points than the commercials polysulfones, in consistent with their rigid structures. Meanwhile, as for the thermal decomposition points of PASs, $\mathrm{Td}_{10}$ of them ranges from 498 to $557^{\circ} \mathrm{C}$ (for $\mathrm{R}=\mathrm{H}$ ) or from 420 to $447^{\circ} \mathrm{C}$ (for $\mathrm{R}=\mathrm{Me}$ ) (Table I shows the data for $\mathrm{Td}_{5}$ ). Therefore, PASs are thermally stable similarly to the commercial polysulfones, if PASs have no methyl group on the aromatic rings, although $M_{\mathrm{w}}$ of PASs is not optimized. Thus, the introduction of the fluorene skeleton is found to contribute to the 


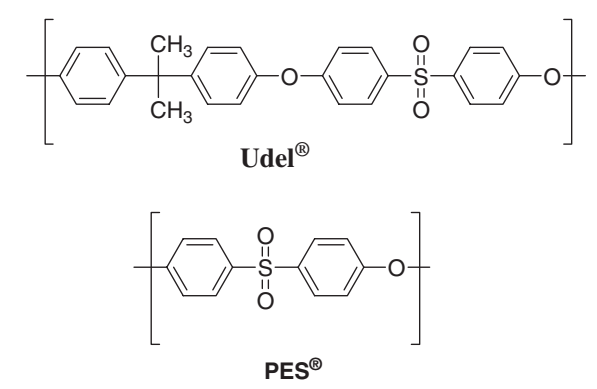

Figure 3. Example of commercial polysulfone.

thermal stability of polysulfones. Solubility of PASs is listed in Table II. Despite the fact that PASs have the rigid polymer main chains by the sulfone groups which correspond to the high glass transition temperature, PASs retained their good solubility in various organic solvents such as chloroform, dichloromethane, NMP, and nitrobenzene. Compared with the corresponding PTEs which are insoluble in highly polar solvents such as DMF and DMSO, PASs showed good solubility in DMF and DMSO, being in consistent with the high polarity of PASs. The high solubility of PASs can be attributed mainly to its kink main chain structure involving $\mathrm{sp}^{3}$ hybridized carbon at the 9-position of the fluorene unit where the molecular space for solvation would be emerged by the perpendicular orientation between the aryl and fluorene moieties. Namely, it is called the "cardo" structure of the 9,9-diarylfluorene moiety. PASs were insoluble in toluene and THF except for PAS2 and PAS7. It is concluded that low solubility of polysulfone polymer can be improved by the introduction of some groups capable of enhancing solvation such as the 9,9-diarylfluorene moiety producing molecular space. Since PASs had good solubility, transparent and strong thin films of PASs could readily be prepared by casting from chloroform solution. All films were self-standing and transparent but somewhat brittle.
In comparison with related aromatic poly(thioether) analogue (PTEs), the PASs films showed slightly higher strong film than their PTEs analogues. Figure 4 illustrated some of the UV-vis spectra of the PASs films in the wavelength region ranging from 200 to $700 \mathrm{~nm}$. All PASs had good transparency in a visible region: the transmittance at $450 \mathrm{~nm}$ was over $80 \%$. The cut off wavelength was $c a .320-334 \mathrm{~nm}$ for PASs. The transparency of PASs would come from their amorphous nature presumably owing to the cardo structure of the fluorene moiety in the main chain. In summary, high performance poly(arylene sulfone)s (PASs) containing 9,9-diarylfluorene moiety in the main chain were synthesized via the oxidation of poly(arylene thioether)s (PTEs) with hydrogen peroxide in formic acid. PASs possessed high thermal stability with decomposition temperatures above $400{ }^{\circ} \mathrm{C}$ under nitrogen atmosphere. The introduction of the sulfone groups increased the glass transition temperature by $40-80^{\circ} \mathrm{C}$ compared with those of the corresponding PTEs. PASs showed high solubility in spite that they involve the sulfone groups. By casting the PAS solution, good transparent thin films were obtained.

\section{EXPERIMENTAL SECTION}

\section{Measurements}

${ }^{1} \mathrm{H}$ NMR spectra were recorded on a JEOL GTX400 spectrometer using $\mathrm{CDCl}_{3}$ as the solvent with tetramethylsilane as the internal standard. Molecular weight and its distribution were estimated by GPC on a JASCO Gulliver system equipped with two consecutive linear polystyrene gel columns (Tosoh TSKgel $\mathrm{G} 5000 \mathrm{H}_{\mathrm{XL}}, \mathrm{G} 4000 \mathrm{H}_{\mathrm{XL}}$ ) at $30^{\circ} \mathrm{C}$ (flow rate $0.085 \mathrm{~mL} / \mathrm{min}$ ) using polystyrene standards and chloroform as the eluent. The glass transition temperature $\left(\mathrm{T}_{\mathrm{g}}\right)$ was determined with a Shimadzu DSC-60 instrument at a heating rate of $10^{\circ} \mathrm{C} / \mathrm{min}$ under a

Table II. Solubility of Polysulfones PASs ${ }^{\mathrm{a}, \mathrm{b}}$

\begin{tabular}{ccccccccccc}
\hline \multirow{2}{*}{ Polymer } & \multicolumn{10}{c}{ Solvent } \\
\cline { 2 - 10 } & $\mathrm{NMP}$ & $\mathrm{CHCl}_{3}$ & $\mathrm{DMAc}$ & $\mathrm{THF}$ & $\mathrm{CH}_{2} \mathrm{Cl}_{2}$ & Benzene & Toluene & Nitrobenzene & DMSO & DMF \\
\hline PAS1 & ++ & + & ++ & - & + & - & - & ++ & ++ & ++ \\
PAS2 & ++ & ++ & ++ & ++ & ++ & \pm & - & ++ & ++ & ++ \\
PAS3 & ++ & ++ & ++ & - & ++ & - & - & ++ & ++ & ++ \\
PAS4 & ++ & ++ & ++ & - & ++ & - & - & ++ & ++ & ++ \\
PAS5 & ++ & ++ & ++ & - & ++ & - & - & ++ & ++ & ++ \\
PAS6 & ++ & ++ & ++ & - & + & - & - & ++ & ++ & ++ \\
PAS7 & ++ & ++ & ++ & ++ & ++ & + & - & ++ & ++ & ++ \\
PAS8 & ++ & ++ & ++ & - & ++ & - & - & ++ & ++ & ++ \\
PAS9 & ++ & ++ & ++ & - & ++ & - & - & ++ & ++ & ++ \\
PAS10 & ++ & ++ & ++ & - & ++ & - & - & ++ & ++ & ++ \\
\hline
\end{tabular}

${ }^{\mathrm{a}} \mathrm{Key}:++$, soluble; + , slowly soluble; \pm , partially soluble on heating; - , insoluble. ${ }^{\mathrm{b}}$ Solubility test was carried out by using $3 \mathrm{mg}$ of polymer and $1 \mathrm{~mL}$ of solvent. 


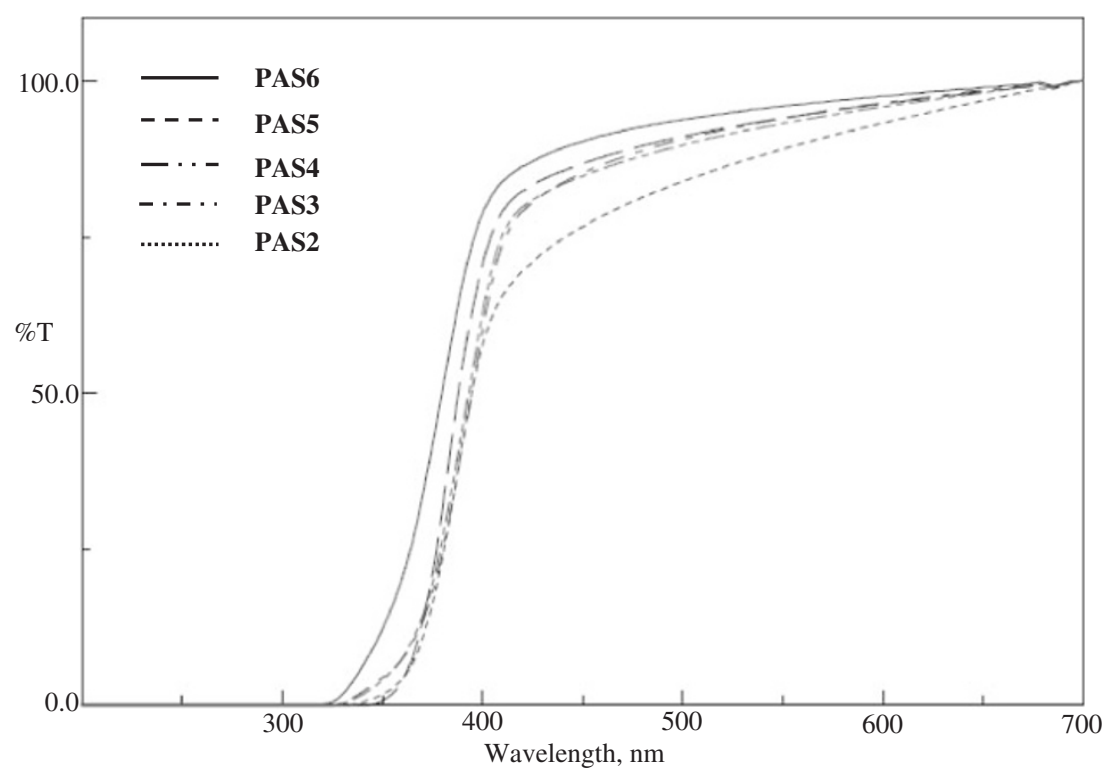

Figure 4. Transmittance of PAS2, 3, 4, 5, and 6 in film state.

nitrogen flow of $50 \mathrm{~mL} / \mathrm{min}$. The thermogravimetric analysis (TGA) was performed with a Shimadzu TGA-50 instrument at a heating rate of $10^{\circ} \mathrm{C} / \mathrm{min}$ under nitrogen atmosphere and in air atmosphere (flow rate $50 \mathrm{~mL} / \mathrm{min}$ ). Transparency was measured by UV-vis spectroscopy on a JASCO Ubest V-560 spectrophotometer. Solubilities of PASs were determined using $3 \mathrm{mg}$ of polymer and $1 \mathrm{~mL}$ of solvents. FT-IR spectra were recorded on a JASCO FT-IR230 spectrophotometer.

\section{Materials}

PTEs 1-10 were prepared in quantitative yields according to our previous report. ${ }^{8}$

PTE1 $\left(M_{\mathrm{n}} 44,000, M_{\mathrm{w}} 98,000\right.$ MWD 2.3), PTE2 $\left(M_{\mathrm{n}} 40,000, M_{\mathrm{w}} 128,000\right.$, MWD 3.2), PTE3 $\left(M_{\mathrm{n}}\right.$ 15,900, $M_{\mathrm{w}} 33,000$, MWD 2.0), PTE4 $\left(M_{\mathrm{n}} 36,000\right.$ $M_{\mathrm{w}} 108,000$, MWD 2.8), PTE5 $\left(M_{\mathrm{n}} 19,000, M_{\mathrm{w}}\right.$ 60,900, MWD 3.2), PTE6 $\left(M_{\mathrm{n}} 15,900, M_{\mathrm{w}} 34,000\right.$, MWD 2.1), PTE7 $\left(M_{\mathrm{n}} 25,000, M_{\mathrm{w}} 72,500\right.$, MWD 2.9), PTE8 $\left(M_{\mathrm{n}} 12,000, M_{\mathrm{w}}\right.$ 28,800, MWD 2.4), PTE9 $\left(M_{\mathrm{n}} 17,000, M_{\mathrm{w}} 35,700\right.$, MWD 2.1$)$, PTE10 $\left(M_{\mathrm{n}} 31,000, M_{\mathrm{w}} 105,000\right.$, MWD 3.4). The reagent and chemicals for preparation of monomer and polymer were purchased from aldirch and used as received without further purification.

Typical Procedure for the Synthesis of Poly(arylene sulfone) $(P A S)^{6}$

In a $25 \mathrm{~mL}$ round bottom flask, PTE5 $(0.50 \mathrm{~g})$ was suspended in $10 \mathrm{~mL}$ of $90 \%$ formic acid. To the suspension was added dropwise $5.0 \mathrm{~g}$ of $30 \%$ hydrogen peroxide at $50^{\circ} \mathrm{C}$. After stirring for $2 \mathrm{~h}$ at $50^{\circ} \mathrm{C}$, the white product was filtered, washed with methanol, and dried at $80^{\circ} \mathrm{C}$ in vacuo for $24 \mathrm{~h}$ to give PAS5.
${ }^{1} \mathrm{H}$ NMR $\left(400 \mathrm{MHz}, \mathrm{CDCl}_{3}\right): \delta 8.02(\mathrm{~d}, 4 \mathrm{H}, J=8.1$ $\mathrm{Hz}, \mathrm{Ar}-\mathrm{H}), 7.84-7.76(\mathrm{~m}, 14 \mathrm{H}, \mathrm{Ar}-\mathrm{H}), 7.39-7.21$ $(\mathrm{m}, 12 \mathrm{H}, \operatorname{Ar}-\mathrm{H}), 7.12(\mathrm{~d}, 4 \mathrm{H}, J=8.1 \mathrm{~Hz}, \operatorname{Ar}-\mathrm{H})$. ${ }^{13} \mathrm{C}$ NMR $\left(400 \mathrm{MHz}, \mathrm{CDCl}_{3}\right): \delta 193.7,160.2,151.1$, $148.5,144.3,140.1,139.5,132.7,132.0,130.2$, $128.9,128.6,128.3,128.0,127.8,125.8,120.7$, $118.8,65.2$.

\section{Preparation of Cast Film: General Procedure}

One of PASs was dissolved in chloroform, so as to give $3 \mathrm{wt} \%$ solution. The solution was filtered through membrane filter (pore size $0.45 \mu \mathrm{m}$ ) and casted on a Teflon plate. The plate was allowed to stand at room temperature for $24 \mathrm{~h}$. The resulting film was further dried in a drying oven at $60^{\circ} \mathrm{C}$ for $24 \mathrm{~h}$.

Acknowledgment. The authors thank for the financial support (basic research (A) 18205014) from the Ministry of Education, Science, Technology, Sports, and Culture of Japan.

\section{REFERENCES}

1. a) P. E. Cassidy, "Thermally Stable Polymer," Marcel Dekker, New York, 1980.

b) A. Duda and S. Penczek, Encycl. Polym. Sci. Eng., 16, (1989).

c) R. N. Johnson, A. G. Farnham, R. A. Callendinning, W. F. Hale, and C. N. J. Merian, J. Polym. Sci., Part A: Polym. Chem., 5, 2375 (1967).

2. a) M. E. A. Cudby, R. G. Faesy, B. E. Jennings, M. E. B. Jones, and J. B. Rose, Polymer., 6, 598 (1965).

b) D. Poppe, H. Frey, K. D. Kreuer, A. Heinzel, and R. Mulhaupt, Macromolecules, 35, 7936 (2002).

c) Y. Yang, P. Wang, and Q. Zheng, J. Polym. Sci., Part B: Polym. Phys., 44, 879 (2006). 
d) K. Miyatake, Y. Chikashige, and M. Watanabe, Macromolecules, 36, 9691 (2003).

e) K. B. Wiles, V. A. Bhanu, F. Wang, M. A. Hickner, and J. E, Polym. Prepr. (Am. Chem. Soc., Div. Polym. Chem.), 44, 1089 (2003).

3. a) C. Berti, A. Celli, E. Marianucci, and M. Vannini, Eur. Polym. J., 41, 1812 (2005).

b) F. A. Bottino, A. R. Cinquegrani, G. D. Pasquale, L. Lucrezia, and A. Pollicino, Eur. Polym. J., 39, 2203 (2003).

4. M. Ueda and T. Ito, Polym. J., 23, 297 (1991).

5. R. Mulhaupt, F. P. Glatz, J. D, Schultze, and J. Springer, Polym. Prepr. (Am. Chem. Soc., Div. Polym. Chem.), 33, 203 (1992).

6. A.-A. G. Shaikh and A. S. Hay, J. Polym. Sci., Part A: Polym. Chem., 40, 496 (2002).
7. a) S. Setayesh, A. C. Grimdale, T. Weil, V. Enkelmann, K. Mullen. F. Meghdadi. E. J. W. List, and G. Leising, J. Am. Chem. Soc., 123, 946 (2001).

b) D. Marsizky, R. Vestberg, P. Blainey, B. T. Tang, C. J. Hawker, and K. R. Carter, J. Am. Chem. Soc., 123, 6965 (2001).

c) G. Klarner, J.-I. Lee, V. Y. Lee, E. Chan, J.-P. Chen, A. Nelson, D. Markiewicz, R. Siemens, J. C. Scott, and R. D. Miller, Chem. Mater., 11, 1800 (1999).

8. S. Seesukphronrarak and T. Takata, J. Polym. Sci., Part A: Polym. Chem., in press.

9. S. Matsumura, N. Kihara, and T. Takata, High Perform. Polym., 13, S293 (2001).

10. Y.-K. Han, S. D. Chi, and Y. H. Kim, Macromolecules, 28, 916 (1995). 